\title{
A NATUREZA DA GESTÃO UNIVERSITÁRIA: INFLUÊNCIA DE ASPECTOS POĹTICO-INSTITUCIONAIS, ECONÔMICOS E CULTURAIS
}

\author{
THE NATURE OF UNIVERSITY MANAGEMENT: \\ INFLUENCE OF POLITICAL-INSTITUTIONAL, ECONOMIC AND CULTURAL ASPECTS
LA NATURALEZA DE LA GESTIÓN UNIVERSITARIA:
INFLUENCIA DE ASPECTOS POLÍTICOS-INSTITUCIONALES,
ECONOMICOS Y CULTURALES

\section{Raimunda Maria da Cunha Ribeiro}

\begin{abstract}
RESUMO: A universidade é um propício espaço de produção de conhecimento para contribuir com a busca de soluções para os problemas que mais atingem a humanidade. O objetivo deste estudo nos remete a analisar a natureza da gestão da universidade pública no Brasil, assim como identificar os condicionantes políticoinstitucionais e culturais presentes no discurso institucional de forma a compreender a natureza, os princípios, os objetivos e as finalidades e a missão desta instituição. Para tanto, dividimos a pesquisa em duas etapas: a primeira etapa trata de uma análise de cunho teórico, a partir de um levantamento de produções acadêmicocientíficas na base de dados da Capes (3 dissertações) e Scielo (4 artigos) entre os anos 2011 e 2016; a segunda etapa é o resultado de um estudo analítico, a partir de documentos institucionais das universidades pesquisadas (federais e estaduais sediadas nas capitais), o Estatuto e o Plano de Desenvolvimento Institucional sobre: princípios, objetivos e finalidade e missão. Os dados foram analisados a partir da técnica de análise de conteúdos na perspectiva de Bardin (2009). Os resultados apontam que a natureza a gestão universitária é construída segundo condicionantes político-institucionais, econômicos e culturais; e que estão articulados de forma a delinear a estrutura e funcionamento da gestão, como também de toda a política universitária.
\end{abstract}

PalavRAS-Chave: Universidade. Gestão. Missão.

\begin{abstract}
The university is a conducive space for the production of knowledge to contribute to the search for solutions to the problems that affect humanity. The purpose of this study is to analyze the nature of the management of the public university in Brazil, as well as to identify the political-institutional and cultural constraints present in the institutional discourse in order to understand the nature, principles, objectives and purposes and mission This institution. To do so, we divided the research into two stages: the first stage deals with a theoretical analysis, based on a survey of academic-scientific productions in the Capes database ( 3 dissertations) and Scielo (4 articles) between the years 2011 and 2016; The second stage is the result of a more analytical study, based on institutional documents of the researched universities (federal and state based in the capitals), the Statute and the Institutional Development Plan on: principles, objectives and purpose and mission. The data were analyzed using the content analysis technique from the perspective of Bardin (2009). The results indicate that the nature of university management is built according to political, institutional, economic and cultural constraints; and they are articulated in order to delineate the structure and functioning of management, as well as of all university politics.
\end{abstract}

KEYWORDS: University. Management. Mission.

RESUMEN: La universidad es un propicio espacio de producción de conocimiento para contribuir con la búsqueda de soluciones a los problemas que más afectan a la humanidad. El objetivo de este estudio nos remite a

Submetido em: 02/07/2017 - Aceito em: 09/07/2017 - Publicado em: 14/07/2017.

v.3

n.2

p.357-278


analizar la naturaleza de la gestión de la universidad pública en Brasil, así como identificar los condicionantes político-institucionales y culturales presentes en el discurso institucional para comprender la naturaleza, los principios, los objetivos y las finalidades y la misión De esta institución. Para ello, dividimos la investigación en dos etapas: la primera etapa trata de un análisis de cuño teórico, a partir de un levantamiento de producciones académico-científicas en la base de datos de Capes (3 disertaciones) y Scielo (4 artículos) entre los años 2011 y 2016; La segunda etapa es el resultado de un estudio analítico, a partir de documentos institucionales de las universidades investigadas (federales y estatales con sede en las capitales), el Estatuto y el Plan de Desarrollo Institucional sobre: principios, objetivos y finalidad y misión. Los datos fueron analizados a partir de la técnica de análisis de contenidos en la perspectiva de Bardin (2009). Los resultados apuntan que la naturaleza la gestión universitaria es construida según condicionantes político-institucionales, económicos y culturales; Y que están articulados para delinear la estructura y funcionamiento de la gestión, así como de toda la política universitaria.

PALABRAS ClAVE: Universidad. Gestión. Misión.

\section{INTRODUÇÃO}

Fortemente pressionada por forças externas advindas de organismos transnacionais, do mercado competitivo e influências do Estado controlador, e também, de forças internas relacionadas à governança acadêmica, a universidade tem sido posta em xeque. A universidade é uma instituição secular, não somente tem acompanhado a história da humanidade, como também, de igual modo, tem influenciado e sido influenciada pela sociedade. Parte de sua história tem sido a de um aprendizado em relação a como se adequar a seu tempo, ou seja, de como reconfigurar sua gestão para se ver alinhada ao modelo político, econômico e cultural de seu contexto.

Há a necessidade de buscarmos novas formas de gestão para esta instituição, com estruturas mais flexíveis, processos decisórios mais ágeis, menos burocracia e liderança mais efetiva. Entretanto, a universidade, em especial a pública, não precisa se servir do expediente da organização, cujos padrões estruturais, tanto dos professores quanto dos comportamentos, se enquadram nos modelos e paradigmas da gestão empresarial.

O objetivo deste estudo, portanto, é analisar a natureza da gestão da universidade pública no Brasil, assim como identificar os condicionantes político-institucionais e culturais presentes no discurso institucional, mais precisamente no Estatuto e no Plano de Desenvolvimento Institucional, de forma a compreender a natureza, os princípios, os objetivos e as finalidades e a missão desta instituição. Dividimos a pesquisa em duas etapas.

A primeira etapa trata de uma análise de cunho teórico, a partir da literatura. Para tanto, fizemos um levantamento de produções acadêmico-científicas na base de dados da Capes e Scielo entre os anos 2011 e 2016. Os documentos encontrados foram, relativamente poucos, porém válidos para apontar por onde e para onde está caminhando o debate da literatura sobre a natureza da gestão e a missão da universidade pública brasileira. No total foram 07 produções, sendo 03 da base Capes (dissertações) e 04 da base Scielo (artigos). Após a leitura

v.3

n.2

p.357-278

maio/ago. 2017


e análise dos documentos foi feita uma triagem de contextos, aqui identificados como unidades de análise: conhecimento; a universidade impulsionada pela economia de marcado; gestão e planejamento estratégico.

A segunda etapa é o resultado de um estudo analítico, a partir de documentos institucionais das universidades pesquisadas (federais e estaduais sediadas nas capitais): o Estatuto e o Plano de Desenvolvimento Institucional. Foram analisados 27 Estatutos de universidades federais brasileiras, sendo que somente 22 Estatutos continham o item denominado "princípios institucionais". Portanto, as categorias foram elaboradas a partir dos textos de 22 documentos. Dos 26 estados da federação, 4 não têm universidade estadual: Acre, Rondônia, Espírito Santo e Sergipe (por ocasião da pesquisa). Das 22 universidades, apenas uma não havia concluído o Estatuto. Portanto, foram analisados 21 Estatutos das universidades estaduais, somando, então, 43 documentos, em se tratando do item "princípios". Em relação ao item "objetivos e finalidades, foram analisados 27 documentos das universidades federais e 21 documentos das universidades estaduais. Nos Planos de Desenvolvimento Institucional foi analisada a declaração de missão, incluindo as universidades federais e as estaduais (com sede nas capitais).

A abordagem de pesquisa escolhida para a realização deste estudo foi qualitativa-quantitativa. O conjunto de dados quantitativos e qualitativos, não apresentam diante de um contexto de oposição, mas de complementaridade, pois segundo Minayo (2001), a realidade abrangida por eles interage dinamicamente, excluindo qualquer dicotomia. A pesquisa buscou envolver o uso e coleta de uma variedade de materiais empíricos (DENZIN; LINCOLN, 2006) para, então, entender o significado da natureza da gestão universitária e os seus condicionantes político-institucionais, econômicos e culturais. Os dados foram analisados a partir da técnica de análise de conteúdos na perspectiva de Bardin (2009).

\section{A ORGANIZAÇÃo dA GESTÃo UNIVERSITÁRIA: DEBATE EM CONSTRUÇÃo}

A organização da gestão da universidade na sociedade do conhecimento demanda que tomemos como pontos de observação os seguintes aspectos, os quais, não restam dúvidas, influenciam sobremaneira a forma como esta instituição tem se organizado, como também, a forma como tem se percebido no contexto sociopolítico, cultural e econômico atual: o planejamento, o uso da tecnologia, a atividade de pesquisa, a reconfiguração da gestão, a influência do mercado.

O esquema 1 apresenta alguns elementos, os quais formam um corpo conceitual acerca do entendimento do novo paradigma da gestão universitária, os quais serão discutidos na sequência.

v.3

n. 2

p.357-278




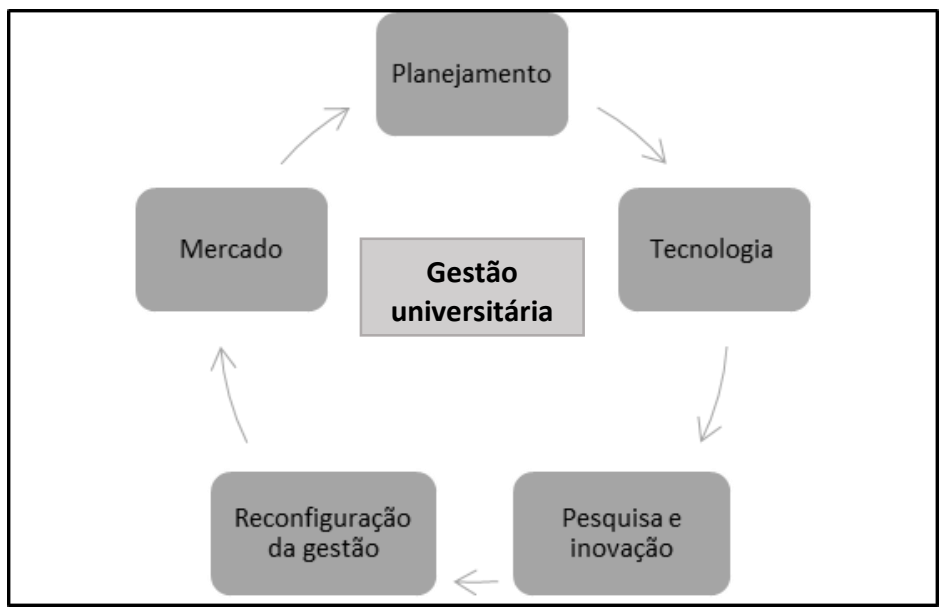

Figura 1. Organização da gestão universitária Fonte: Construção da autora.

Ao pensarmos em boas práticas de gestão, e não apenas para a universidade, mas em qualquer instituição ou organização, recorremos à ideia de adoção do planejamento estratégico como forma de execução dessas práticas. A experiência do planejamento estratégico é realidade em boa parte das universidades públicas brasileiras, como um pressuposto, segundo Scaglione e Nitz (2013), de que a estratégia é um raciocínio que liga à situação externa, visto que o primeiro momento da formulação estratégica considera as variáveis ambientais que influenciam a instituição. A gestão estratégica exige mudança de comportamento da universidade, de uma instituição elitista e burocrática para uma instituição atenta às mudanças no cenário político, econômico e social nacional e internacional.

O uso da tecnologia tem contribuído para a universidade se adequar em relação à materialização do planejamento estratégico, que implica, pois, um novo modelo de gestão. Um exemplo na realidade de universidades públicas brasileiras é a adesão ao conceito de Business Intelligence (BI), na tradução para o português significa inteligência nos negócios, como ferramenta subsidiária na gestão da informação. Autores, como Barbieri (2001) e Turban et al. (2009) reconhecem a importância dessa ferramenta no que diz respeito à sua capacidade de promover a estruturação correta de informações em depósitos, permitindo a sua manipulação com maior facilidade. O BI pode ser usado nas empresas e também nas IES para ajudar na gestão, concernente à agilidade com que detém as informações e à tomada de decisão.

No cenário do ensino superior é notável o papel da investigação científica e da inovação tecnológica na sociedade do conhecimento. A tendência é que essas questões cresçam junto com os fenômenos da globalização e da internacionalização da Educação Superior, em que pesem críticas de submissão às economias globalizadas e às exigências de uma vigilância crítica (BORDIGNON; AFONSO; FRANCO, 2012). Esta tendência não deixa de despertar 
certa tensão no debate, porque são questões cujos conceitos se configuram como polissêmicos.

Ferreira (2002) considera que as universidades brasileiras têm sido cobradas constantemente por tecnocratas do governo pela defasagem da tecnologia do país e de produzirem um número de patentes per capita reduzido. Dados de suas pesquisas nos levam a compreender a lógica da competitividade no campo da educação superior, em nome da busca exagerada pela produção científica do conhecimento, redirecionada pela lógica da economia globalizada. Partindo desse pressuposto, é forçoso admitir que a maioria das universidades públicas brasileiras não tem autonomia de gestão financeira, por isso há sempre o risco de comprometer suas atividades básicas e cumprir seu papel no desenvolvimento da nação.

Não nos furtamos de admitir, porém, conforme argumenta Magalhães et al. (2014), que as instituições de ensino superior fazem uso de sua autonomia estatutária para definir sua missão, elaborar os estatutos, gerir recursos e desenvolver atividades numa lógica de autogestão. Reconhecemos, entretanto, que a autonomia institucional foi amplamente assumida como um instrumento de regulação, por vezes, com o objetivo de implementar modelos de gestão que possam responder adequadamente a ambientes competitivos.

Alguns atributos são indispensáveis à gestão universitária neste terceiro milênio: a democracia participativa, a autonomia, o financiamento, a excelência acadêmica e a formação dos gestores. O modelo de universidade, no contexto atual, para além da reconfiguração de sua gestão, nos permite refletir sobre duas questões fundamentais: mercado e sociedade.

A visão econômica pela qual tem tomado conta do discurso imposto à universidade tem limitado esta instituição à função mercadológica, ou seja, de adequação ao mercado e seu imperativo capitalista. Dias Sobrinho (2005), ao discutir sobre os dilemas da educação superior, o faz dizendo que estão postos pela manifestação da crise estrutural do Estado, que não consegue prover as instituições das condições necessárias à promoção da equidade e da justiça social, ao passo que situa o grande dilema da educação superior: educação como direito social e bem comum ou educação como negócio e mercadoria. Nesta discussão, Chauí (2003) reconhece que a universidade é fundamentalmente marcada por contradições, opiniões, atitudes e projetos conflitantes, e que, dessa forma, marca sua relação com a sociedade. Correia, Amaral e Magalhães (2000) reconhecem que o desenvolvimento da educação superior deixou de estar ligado à modernização liderada pelo setor público e passou a vincular-se ao setor privado, substituindo as formas tradicionais de regulação por mecanismos de mercado como instrumentos de política pública, acirrando a competição entre os pares e entre as instituições na procura de soluções tanto mais eficazes quanto mais econômicas. 
O debate, também, nos leva a voltar nosso olhar para a universidade enquanto vetor de desenvolvimento social, cultural e econômico do Estado. Assim, nos apoiamos nas ideias de Goergen (2006) e reconhecemos que devemos esperar da universidade, que ela produza conhecimentos úteis e também forme pessoas capazes de atender aos quesitos de um mundo laboral pela ciência e pela tecnologia. A bem da verdade, a universidade está atrelada ao contexto social, portanto, precisa estar atenta às demandas de seu tempo: velocidade e caráter permanente das transformações; crescimento da quantidade de conhecimentos e informações disponíveis; capacidade extremamente grande de armazenamento e de transmissão de conhecimentos e informações num espaço e tempo cada vez menores. E, ciente de seu papel social e educacional, ser capaz de adaptar-se e integrar-se àquilo que é inovador em cada época.

Ressaltamos que a gestão universitária é influenciada tanto por fatores internos quanto por fatores externos. O Quadro 1 é um demonstrativo de aspectos influentes na gestão universitária: político-institucionais, econômicos e culturais.

Quadro 1. Aspectos influentes na gestão universitária

\begin{tabular}{|c|c|}
\hline \multicolumn{2}{|c|}{ Aspectos influentes na gestão universitária } \\
\hline \multirow{7}{*}{ 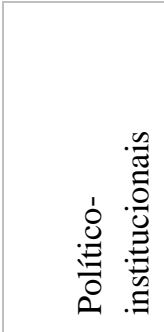 } & Visão empreendedora \\
\hline & Sistemas de Informação (SI) \\
\hline & A reforma de governo e a narrativa da nova gestão pública (gerencialista). \\
\hline & Métodos de gestão: Balanced Scorecard, Mapa de Rede de Impactos. \\
\hline & Práticas gerenciais empresariais e racionalidade na gestão universitária. \\
\hline & Dispositivos de vigilância, controle e adestramento (dressage) da prática docente \\
\hline & Institucionalização da responsabilidade social universitária. \\
\hline \multirow{6}{*}{ 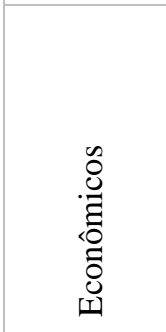 } & A investigação científica e a inovação educacional de base tecnológica \\
\hline & Perspectiva de competitividade. \\
\hline & Incorporação da missão de apoio ao desenvolvimento econômico. \\
\hline & $\begin{array}{l}\text { Implantação de Parques Científicos e Tecnológicos, cujo objetivo e estreitar as relações } \\
\text { universidade-empresa. }\end{array}$ \\
\hline & Produção e comercialização das patentes universitárias. \\
\hline & Formação empresarial de estudantes \\
\hline \multirow{6}{*}{ } & O planejamento \\
\hline & A gestão implica liderança e habilidade gerencial. \\
\hline & Valores culturais facilitam ou não um processo de mudança na gestão. \\
\hline & As influências de uma gestão empresarial profissional no clima organizacional. \\
\hline & O ambiente externo de mudança e orientações de organismos transnacionais. \\
\hline & Práticas de desenvolvimento sustentável e responsabilidade social \\
\hline
\end{tabular}

Fonte: Construção da autora. 
$\mathrm{Na}$ esteira das discussões sobre gestão universitária, incluindo a tendência da universidade empreendedora, presente um pouco por todo o globo, é possível identificarmos alguns aspectos que, de forma direta ou indireta, influenciam na estrutura e no funcionamento da gestão, nas tomadas de decisões e, em consequência, na elaboração e execução da política universitária.

Em uma perspectiva didática, os aspectos estão separados em três eixos ou dimensões: político-institucionais, econômicos e culturais. A universidade que outrora já foi uma instituição clássica e de caráter elitista, precisa rever seus próprios conceitos, seu papel no contexto social e sua influência no processo de desenvolvimento da nação. Os fundamentos universais e generalistas da universidade tradicional, incompatíveis com as exigências sociais emergentes, passam a ser substituídos por outros, paulatinamente introduzidos no modus vivendi da universidade contemporânea, como, por exemplo, podemos citar: parcerias com os setores produtivos, atenção às necessidades do Estado e da sociedade. Buarque (2003), ao se referir à universidade como vanguardista, assinala algumas premissas: produtora crítica do conhecimento; instituição capaz de assegurar o futuro de seus alunos; recuperar o papel de principal centro de distribuição de conhecimento (científico, tecnológico e humanístico); assumir compromisso de responsabilidade social e ética para com o futuro de uma humanidade sem exclusão; reconhecer-se como uma instituição aberta, com forte presença na rede mundial.

A universidade é uma instituição complexa, com traços típicos que a constitui, fundamentalmente, diferente de outras instituições, embora no mesmo âmbito da esfera pública. Por isso, a forma como se organiza do ponto de vista da gestão, é marcada por peculiaridades, o que não significa, potencialmente, distorção de organização em relação a outras instituições, haja vista que a universidade está agora, mais do que nunca, trazendo para si conceitos e traços do campo da administração e das ciências políticas, principalmente, no que diz respeito à organização e funcionamento da gestão. Para entendermos melhor este sentido da organização da gestão universitária e suas especificidades, buscamos o fundamento apresentado por Vahl (1990), ao reconhecer que as universidades são organizações com uma vasta coleção de compromissos e objetivos, e não se comporta, do ponto de vista organizacional, com a exatidão ou especificidade de uma empresa ou organização semelhante. $\mathrm{O}$ autor considera, inclusive, que seus objetivos são, por vezes, vagos e pouco definidos; são organizações que prestam serviços, servindo clientes com necessidades específicas, com voz ativa e que retornam à sociedade como um todo; é uma instituição que demanda autonomia para a realização de seus trabalhos, inclusive e, principalmente, financeira.

Pires (1996) nos adverte que a universidade é guardiã, por excelência, da produção científica e cultural da sociedade, por isso não deve ter o seu papel limitado apenas a regras de adequação ao mercado, típicas de sua função econômica. Porque, assim entendemos que,

\begin{tabular}{|l|l|l|l|l|l} 
Rev. Inter. Educ. Sup. & Campinas, SP & v.3 & n.2 & p.357-278 & maio/ago. 2017 \\
\hline
\end{tabular}


além de ser presidida pela função econômica, esta é uma instituição que possui também funções sociais, culturais e simbólicas. Querer impor à universidade pública os novos paradigmas organizacionais significa retirar-lhe o princípio de autonomia institucional e o caráter social de sua produção cultural.

Embora, reconheçamos que a universidade é presidida por uma lógica muito mais complexa e abstrata em suas funções sociais, comparando com a lógica que preside e regulamenta a vida empresarial, a universidade, não somente a do setor privado, mas também a do setor público, vê-se no direcionamento de adotar certos conceitos e procedimentos próprios da lógica economicista. É nesta direção que nos adverte Santos (1995), que a lógica economicista consiste em conceber o produto universitário como um produto industrial, ainda em conceber a universidade como uma organização empresarial.

Esta lógica é mais evidente em relação aos aspectos que influenciam a universidade a tornarse cada vez mais uma instituição a serviço do mercado. Podemos perceber essa tendência quando a universidade se deixa influenciar por fatores econômicos, e, dessa forma, prioriza: a investigação científica e a inovação educacional com base tecnológica para o desenvolvimento econômico; delineia suas políticas numa perspectiva de competitividade; prioriza em sua missão o desenvolvimento econômico; estreita as relações com o setor produtivo, muito mais que com o setor social; determina como meta a produção e a comercialização das patentes universitárias; forma seus alunos do ponto de vista empresarial, de forma a atender às demandas do mercado. É, sem dúvida, uma proposta de universidade entendida como atributo de um movimento de aproximação do setor empresarial.

Nesta perspectiva, Silveira e Bianchetti (2016) argumentam que a universidade brasileira, diante do fato de ter como encargos históricos produzir conhecimento novo e, mais recentemente, inovador e gerar pensamento crítico, vem sendo chamada, permanentemente, a modernizar-se e moldar-se aos interesses do capital, formando novos quadros de profissionais e pesquisadores, com diferentes níveis de formação em trabalho interdisciplinar, particularmente, na área científica e tecnológica, incluída a transferência de conhecimento e tecnologia ao setor empresarial.

Outros aspectos podem ser destacados como elementos que influenciam na gestão universitária, são os condicionantes culturais, os quais dizem respeito à forma como a instituição se percebe no contexto social e educacional, com vistas a delinear a estrutura e o funcionamento de sua própria gestão e a sua política universitária de ensino, pesquisa e extensão.

A gestão universitária é delineada por documentos institucionais, os quais estabelecem o viés da política institucional, como é o caso do Regimento Geral, o Estatuto, o Plano de Desenvolvimento Institucional e o Planejamento Estratégico, ou, ainda, como muitas

\begin{tabular}{|l|l|l|l|l|l|} 
Rev. Inter. Educ. Sup. & Campinas, SP & v.3 & n.2 & p.357-278 & maio/ago. 2017 \\
\hline
\end{tabular}


instituições costumam chamar, o Plano de Gestão ou Plano de Trabalho. Quem elabora os documentos institucionais o faz com marcas de uma ideologia que exerce certa influência nas tomadas de decisão, ou seja, é a identificação de valores grupais. Esta concepção de tornar a universidade na perspectiva de gestão profissional decorre de outra época, quando o capitalismo ganha força na sociedade industrial, onde o conhecimento é moeda valiosa para o progresso das sociedades. Silveira e Bianchetti (2016) argumentam sobre esta questão, quando explicam que desde as origens do Estado moderno, a concepção de universidade é atravessada pelo caráter instrumental, no sentido de responder às demandas e aos tempos econômico, industrial, tecnológico e urbano da ordem capitalista. Entretanto, reforçam os autores, ao longo do desenvolvimento histórico dessa concepção, alguns de seus aspectos vão se modificando no que diz respeito às formas de financiamento e de gestão, à configuração institucional e, especificamente, de produção de conhecimento. Isso implica que a universidade pode se tornar instrumento de desenvolvimento econômico, quando seu foco está em, unicamente, preparar o homem para viver a era urbana, industrial, científica e tecnológica. É impossível a universidade não sentir o peso dessa lógica e os consequentes reflexos na política universitária de ensino, pesquisa e extensão, na reconfiguração da gestão, assim como, na institucionalização da avaliação.

E, assim, Mañas (2014) entende que a universidade deve ter suas estruturas e estratégias de tal forma que possa manter o atendimento às demandas cada vez mais concorridas, com a escolha de um diferencial que lhe garanta uma vantagem única. Isso faz a universidade acreditar, por vezes, que a partir dessa estratégia, possa vir a percorrer um caminho que lhe garanta o crescimento e o desenvolvimento a que propõem os seus administradores. Mas, as universidades públicas se veem na encruzilhada entre adotar o novo e conservar o velho, partir para o, até então, desconhecido ou conservar o que, até aqui, vem dando certo. Por isso, mais do que nunca, a universidade precisa se organizar, planejar estrategicamente, firmar suas ações de forma a atingir objetivos e metas, enfim, cumprir sua missão social e educacional em tempos de bruscas transformações econômicas, políticas e culturais. Implica dizer que a universidade precisa estar preparada para as influências, sejam internas, sejam externas que, via de regra, acabam por determinar os caminhos a serem seguidos.

Autores, como Finger (1997) e Meyer Jr. (1991), reforçam algumas críticas à gestão da universidade pública, quando administrada por professores de carreira, por vezes, sem a formação acadêmica própria para tal função, ou seja, a crítica recai sobre a gestão não profissionalizada. Finger (1997) critica dizendo que a universidade brasileira, em sua maioria, tem sido administrada por pessoas de boa vontade. Sua crítica, entretanto, recai mais fortemente sobre a administração da universidade pública, na qual a escolha é muito mais pelo viés político, deixando a instituição à mercê das improvisações como uma prática permanente. Meyer Jr. (1991) também vai nesta direção, que, por causa desse improviso, a administração tem dificuldade de acompanhar os novos conceitos e práticas de gestão, principalmente, quando se trata da gestão profissional.

\begin{tabular}{|l|l|l|l|l|l|} 
Rev. Inter. Educ. Sup. & Campinas, SP & v.3 & n.2 & p.357-278 & maio/ago. 2017 \\
\hline
\end{tabular}


A universidade é uma instituição de estrutura complexa, fundamentalmente marcada, por um lado, por relações de poder e, por outro, pelo corporativismo entre os pares. Por isso, muitos grupos de interesses influenciam as decisões, sendo estas influências do ponto de vista político-institucional, econômico e cultural. Dando segmento a essa discussão, apresentaremos a seguir, alguns apontamentos acerca da natureza da gestão universitária, sob o ponto de vista de documentos institucionais.

\section{A NATUREZA DA GESTÃO: O DISCURSO INSTITUCIONALIZADO}

Esta seção tem como principal objetivo fazer uma análise dos documentos institucionais das universidades pesquisadas: Estatuto e Plano de Desenvolvimento Institucional. Os quadros, a seguir, apresentam um panorama ou visão geral daquilo que os documentos designam ser os princípios, objetivos e finalidades institucionais, os quais servem de fundamentos para a organização da gestão universitária.

A tabela 1 trata de como podemos encontrar dispostos os princípios orientadores das universidades públicas no Brasil, incluindo aqui as IES federais e as IES estaduais, com sede nas capitais do país.

Tabela 1. Visão geral dos princípios nas IES Federais e Estaduais (frequência) a partir dos Estatutos

\begin{tabular}{lcc}
\hline Categorias & $\begin{array}{c}\text { Federais } \\
(\mathbf{\%})\end{array}$ & $\begin{array}{c}\text { Estaduais } \\
(\mathbf{\%})\end{array}$ \\
\hline Conhecimento & 100 & 100 \\
\hline Indissociabilidade ensino, pesquisa e extensão & 100 & 100 \\
\hline Ética, paz, cidadania e direitos humanos & 63 & 33,5 \\
\hline Autonomia e gestão democrática & 55,6 & 62 \\
\hline $\begin{array}{l}\text { Respeito às diferenças e flexibilidade de métodos e } \\
\text { de ideias }\end{array}$ & 48,14 & 57,14 \\
\hline Gratuidade e publicidade & 33,33 & 33,5 \\
\hline Unidade de patrimônio & 33,33 & \\
\hline Desenvolvimento multidimensional & 33,33 & 23,8 \\
\hline
\end{tabular}

Fonte: Estatutos.

Em linhas gerais, as universidades delineiam sua gestão, tomando por base dois princípios fundamentais, que aparecem em todos os documentos analisados: promover e socializar o conhecimento científico, tecnológico, artístico e humanístico, de forma que este objetivo desencadeie no desenvolvimento das ciências, das letras e das artes, na difusão da cultura, da reflexão crítica profissional, direcionadas às necessidades de uma sociedade democrática; a outra categoria está relacionada à indissociabilidade entre o ensino, a pesquisa e a extensão, remetendo para a proposição de ofertar ensino superior visando à habilitação e à qualificação de profissionais para o exercício destas três atividades básicas em todas as áreas do 
conhecimento. Assim, a universidade acredita estar promovendo e fortalecendo a ciência, a tecnologia, a cultura e a arte.

As demais categorias que aparecem nos textos - ética, paz, cidadania e direitos humanos; autonomia e gestão democrática; respeito às diferenças; qualidade e excelência acadêmica; gratuidade e publicidade; unidade de patrimônio; desenvolvimento e sustentabilidade - fazem parte do discurso institucionalizado das IES que, em conformidade com a produção e socialização do conhecimento, e também, como a indissociabilidade do ensino, pesquisa e extensão constituem o viés de elaboração e funcionamento da política universitária e de gestão da universidade pública, constituindo, assim, a sua identidade.

A redefinição da identidade da universidade pública vem se constituindo em razão de alguns fatores básicos. Na linha de entendimento de Catani e Oliveira (1999), esses fatores podem ser descritos da seguinte forma: em primeiro lugar, o governo busca atender às exigências de organismos internacionais, que inclui reduzir, gradualmente, a aplicação de recursos públicos para o financiamento da educação superior; em segundo lugar, as mudanças na conjuntura atual são contínuas e aceleradas, sendo motivadas, basicamente, pela reestruturação produtiva do capitalismo, assentada no processo de globalização do capital financeiro e na revolução técnico-científica-informacional; em terceiro lugar, a necessidade de ampliar a legitimidade institucional e o reconhecimento da relevância social, face às críticas governamentais e da mídia de que as universidades públicas são perdulárias, tem levado a maioria dessas instituições a buscarem maior vinculação com o setor produtivo e com a comunidade local.

Ainda que todos os documentos analisados reforcem a produção do conhecimento como um dos principais princípios das universidades públicas, críticas ainda pesam sobre essa instituição. Chiarini e Vieira (2012) reconhecem que as universidades no Brasil não formam um grupo homogêneo de criação de conhecimento, porque existem universidades mais intensivas na geração e produção de conhecimento científico que outras, ficando a produção do conhecimento, em maior escala, a cargo das universidades públicas. Argumentam, ainda, que nem mesmo as instituições de ensino superior públicas são passíveis de generalizações, reconhecendo, entretanto, que as universidades federais são os principais espaços de produção de conhecimento.

Outras categorias aparecem em menor frequência, como, por exemplo, a autonomia e a gestão democrática, em 55,6\% nos Estatutos das IES federais e 62\% nos das IES estaduais. Trata-se de um preceito legal, garantido e fundamentado na Constituição Federal de 1988, conforme expressa o artigo 207: "As universidades gozam de autonomia didático-científica, administrativa e de gestão financeira e patrimonial, e obedecerão ao princípio da indissociabilidade entre ensino, pesquisa e extensão." Esses números nos indicam que é forçoso admitir que há um descompasso entre os Estatutos e a Constituição, uma vez que verificamos terem sido elaborados após 1988. Outras categorias aparecem em frequência

\begin{tabular}{|l|l|l|l|l|l|} 
Rev. Inter. Educ. Sup. & Campinas, SP & v.3 & n.2 & p.357-278 & maio/ago. 2017 \\
\hline
\end{tabular}


decrescentes, mas não dizemos que em menor grau de importância para a institucionalidade da universidade.

Para efeito de organização, podemos classificar essas categorias em dois grupos. Categorias relacionadas à responsabilidade social da universidade: ética, paz, cidadania (63\% nas IES federais e 33,5\% nas IES estaduais); respeito às diferenças e pluralismo de ideias $(48,14 \%$ nas IES federais e $38 \%$ nas IES estaduais); desenvolvimento multidimensional (33,33\% nas IES federais e $23,8 \%$ nas IES estaduais); compromisso com a sustentabilidade (somente nas IES federais em 22,22\% dos documentos); liberdade para ensinar e aprender (somente nas IES estaduais, em 57,14\% dos documentos). Categorias relacionadas à gestão universitária: avaliação da qualidade e excelência acadêmica (apenas nas IES federais, em $37 \%$ dos documentos); gratuidade e publicidade (33,33\% nas IES federais e 33,5 nas IES estaduais); unidade de patrimônio (33,33 nas IES federais e 38\% nas IES estaduais); racionalidade de organização (somente nas IES estaduais, em 33,5\% dos documentos). Os princípios orientadores das universidades públicas nos remetem para a mesma direção, nos quais percebemos muito mais similaridades que discordâncias. Contudo, cabe assinalar as categorias que aparecem com maior frequência nos documentos das universidades federais em relação às estaduais: ética, paz, cidadania e diretos humanos; respeito às diferenças; desenvolvimento multidimensional. E as categorias que aparecem com maior frequência nos documentos das universidades estaduais em relação às federais: autonomia e gestão democrática; unidade de patrimônio.

O que dizem os documentos institucionais e o que, de fato, orienta a universidade, nos leva a crer que há uma crise de identidade instalada na pluralidade de discursos que habitam em seu interior. Concordamos com os argumentos de Magalhães (2006), quando se refere às narrativas pós-modernas e a natureza do ensino superior e das instituições. As razões da mudança de natureza do ensino superior e das suas instituições não podem ser encontradas no âmbito restrito do ensino superior. Antes, porém, consideramos que a reconfiguração do ensino superior há de ser entendida a partir das transformações que estão a ocorrer nos campos econômico, social e político; mudança de padrões de trabalho, da produção, da distribuição e do consumo.

Diante das contradições e da pluralidade de discursos centrados na universidade, achamos pertinente citar um dos principais desafios desta instituição, segundo Trindade (1998), que implica em como estabelecer o equilíbrio entre qualidade, pertinência e equidade num contexto em que deve formar para o desconhecido. A educação superior, em geral, e a universidade, em particular, parecem estar a submergir no seu contexto social mais amplo e corre o risco de, ao entrar definitivamente no mundo dos negócios, passar a redescrever o mundo em vez de compreendê-lo (MAGALHÃES, 2006). Aqui, quando propomos estabelecer o equilíbrio dentro da universidade e na sua relação com o campo social, é porque reconhecemos que a própria universidade tem se constituído em um campo de disputas e 
ideologias diversificadas. Por um lado, há aqueles que acreditam que a universidade não precisa de mudança; por outro lado, há aqueles que buscam na universidade um espaço de produção de saber, mas também de democracia e proposições para as demandas da sociedade em transformação. A crítica tem recaído sobre a universidade, principalmente, da parte daqueles que a apontam como uma instituição ainda distante das questões de ordem social e política. Dias Sobrinho (2014) está do lado daqueles que acreditam que a universidade não tem conseguido acompanhar as mudanças nos novos modos de produção e distribuição de conhecimentos em contextos de uma voraz explosão epistêmica em diversas áreas, muito menos (nos chama a atenção!) tem conseguido resolver os conflitos ideológicos e políticos dos diferentes grupos de interesse que constituem as múltiplas contradições das formações sociais. Assim, valemo-nos da afirmação de que a universidade pública no Brasil não tem conseguido se constituir em plenitude, nem como instituição de ensino, nem como instituição de pesquisa.

A fundamentação, do ponto de vista filosófico da instituição, é posta no Estatuto abordando os seguintes vieses: princípios, objetivos e finalidades. A tabela 2 apresenta uma visão geral dos objetivos e finalidades que orientam a organização das universidades federais e estaduais no Brasil, em especial, aquelas com sede nas capitais.

Tabela 2.Visão geral dos objetivos e finalidades nas IES Federais e Estaduais a partir dos Estatutos

\begin{tabular}{lcc}
\hline Categorias & $\begin{array}{c}\text { Federais } \\
(\boldsymbol{\%})\end{array}$ & $\begin{array}{c}\text { Estaduais } \\
(\boldsymbol{\%})\end{array}$ \\
\hline Extensão com base no conhecimento científico & 100 & 100 \\
\hline Formação profissional & 89 & - \\
\hline Produção de conhecimento científico e cultural & 82 & 100 \\
\hline Estudos sobre a realidade social & 63 & 29 \\
\hline Promoção do espírito científico e reflexivo & 52 & 100 \\
\hline Promoção do desenvolvimento multidimensional & 41 & - \\
\hline Promoção da consciência cívica nacional & 30 & 33 \\
\hline Cooperação com outras instituições & 26 & 38 \\
\hline Colaboração com as políticas de desenvolvimento & - & 57 \\
governamental & & \\
\hline Integração do homem com o meio & - & \\
\hline \multicolumn{1}{c}{ Fonte: Estatutos. }
\end{tabular}

A tabela acima apresenta uma visão muito semelhante sobre o que as instituições de ensino superior públicas no Brasil elegeram como prioridades, para, de certa forma, definirem seu papel educacional e também social. Como destaque, temos em $100 \%$ dos documentos analisados a extensão com base no conhecimento científico, o que implica que a produção do conhecimento é o principal objetivo das universidades federais e estaduais. Reconhecemos, entretanto, que seu principal objetivo é produzir conhecimento, gerar pensamento crítico, produzir ideias e saberes, formar cidadãos e profissionais. As novas circunstâncias culturais, científicas e tecnológicas impostas pela sociedade do conhecimento tem levado a p.357-278 maio/ago. 2017 
universidade a se posicionar nesta direção, de produzir o conhecimento científicotecnológico, em atendimento à lógica do produtivismo, da competitividade, da eficiência e da excelência acadêmica.

Vale lembrar que a educação tem papel importante no desenvolvimento da consciência crítica e da produção das condições favoráveis dos indivíduos e das sociedades. Nesse sentido, Dias Sobrinho (2015) reconhece a universidade como um dos espaços públicos em que, privilegiadamente, podem e devem vicejar as reflexões, conhecimentos e técnicas, em clima de aceitação das contradições e das diferentes visões de mundo, próprias desse espaço; como instituições mergulhadas nas contradições da liberdade humana e, que por isso, tem enormes potencialidades e graves responsabilidades públicas.

Outras categorias aparecem em 100\% dos Estatutos das universidades estaduais: expansão do ensino e da cultura; realização de pesquisas; realização da extensão. As universidades federais demonstram esta preocupação, mas não tão visível quanto as estaduais, uma vez que estas categorias aparecem em menor frequência. De fato, reconhecemos a universidade como o espaço da produção do saber, para, dessa forma, justificar sua existência diante da sociedade. Do contrário, a universidade perderia sua razão de ser, uma vez que sua vocação é produzir conhecimentos a partir das atividades de pesquisa, transmiti-los por intermédio do ensino e difundi-lo por meio da extensão. Assim, concordamos com Dias Sobrinho (2015) de que a universidade é uma instituição de educação, cuja finalidade principal é a formação em seus distintos graus e dimensões. $\mathrm{O}$ que interessa no final das contas é a sua contribuição na construção do mundo humano a que cada um cabe protagonizar nos planos da individualidade, da sociabilidade e da cidadania.

Mais categorias foram identificadas nos Estatutos quanto aos objetivos e finalidades das universidades federais e estaduais. Vale ressaltar que os objetivos que seguem são quase que totalmente diferentes, ou seja, os que aparecem nos documentos das federais não aparecem dos documentos das estaduais. Ressaltamos uma das categorias que aparece nos Estatutos tanto das universidades federais quanto nos das universidades estaduais: cooperação com outras instituições (26\% nos documentos das federais); cooperação e intercâmbio com outras instituições (38,1\% nos documentos das estaduais). Constatamos, assim, pouca similaridade entre as instituições brasileiras, mesmo em se tratando das instituições públicas. Em frequência decrescente, aqui são apresentadas as categorias das universidades federais: estudos sobre a realidade social (63\%); promoção do espírito científico e reflexivo (52\%); promoção do desenvolvimento multidimensional $(41 \%)$ promoção da consciência cívica nacional (30\%); promoção da integração cultural $(11,11 \%)$. E, em frequência decrescente, apresentamos as categorias que aparecem nos Estatutos das universidades estaduais: integração do homem com o meio (86\%); colaboração com as políticas de desenvolvimento governamental (57,14\%); promoção da paz, solidariedade e direitos humanos $(33,33 \%)$; 
aproveitamento dos recursos naturais e sustentabilidade (33,33\%); busca de solução para os problemas regionais e nacionais $(29 \%)$.

Arriscamo-nos em dizer que tanto as universidades federais quanto as estaduais têm, em alta medida, a preocupação com a produção, difusão e aplicação do conhecimento. Na sequência, suas proposituras nos levam a crer que a universidade pública, de modo geral, apresenta, em certa medida, a preocupação com o desenvolvimento, com a cooperação interinstitucional, espírito crítico, cidadania, política e sustentabilidade. Podemos ainda nos arriscar em dizer que estas preocupações formam a responsabilidade primeira da universidade, assim como considera Dias Sobrinho (2015): construir a qualidade dos processos sem perder de vista os seus fins essenciais. Implica, pois, cumprir suas atividades de formação e de trato com o conhecimento com o maior grau possível de qualidade acadêmica, científica, técnica, moral, política e social. Em outras palavras, o autor quer dizer que o eixo da responsabilidade das instituições deve consistir essencialmente na formação de indivíduos-cidadãos dotados de valores cívicos e conhecimentos técnica e cientificamente relevantes e socialmente pertinentes. Dessa forma, entendemos que a universidade está se inserindo, pelo menos do ponto de vista dos documentos institucionais, no contexto social, político, econômico, cultural e ambiental, adequando suas propostas e documentos jurídicos de forma a regulamentar as práticas relacionadas às suas atividades básicas de ensino, pesquisa e extensão e alcançar seus principais objetivos.

A universidade não é uma empresa, portanto, não deve se orientar por princípios meramente econômicos, embora sua relação com o setor produtivo esteja cada vez mais estreita. Uma das críticas mais severas que recai sobre a universidade, inclusive a do setor público, é direcionar todos os seus esforços para a produção da pesquisa científica, em nome do conhecimento, por considerar que sua visibilidade social passa apenas por este viés, uma vez que o conhecimento revela moeda de valor cada vez mais forte na sociedade atual, inclusive sua relação com o fortalecimento do campo econômico. Cabe ressaltar o que Santos (2005) argumenta sobre a relação da universidade e a sociedade da informação. Para ele, por mais referenciada em códigos de conhecimento e informação, a sociedade humana da atualidade continua estruturada sobre profundas contradições políticas e perversas desigualdades sociais. E neste tocante, a universidade tem o papel de ser capaz de atuar como instrumento de integração social e política entre países, culturas e povos. Implica, pois, a capacidade da universidade em conduzir um projeto social e epistemológico adequado à superação das decorrências da globalização neoliberal da economia.

A universidade tem o compromisso e a responsabilidade com o desenvolvimento social e econômico. Importa, pois, relembrar a necessidade de manter o equilíbrio em sua missão e não estar excessivamente a serviço dos interesses do capital e da política neoliberal. Goergen (2006), quando trata de compromisso social da universidade, chama a atenção para o exercício da crítica, da oposição e da resistência. Para o autor, compromisso social não pode

\begin{tabular}{|l|l|l|l|l|l|} 
Rev. Inter. Educ. Sup. & Campinas, SP & v.3 & n.2 & p.357-278 & maio/ago. 2017 \\
\hline
\end{tabular}


ser interpretado somente sob o aspecto operacional sistêmico, mas deve, também, ter em vista o contexto social mais amplo que envolve tanto a instituição de uma sociedade mais justa e igualitária quanto a realização integral do ser humano como indivíduo e cidadão.

Afinal, o que quer a universidade enquanto instituição social e educacional? Se não há uma resposta totalizadora para esta pergunta, arriscamo-nos em dizer que a universidade tem como principal objetivo para com a comunidade acadêmica e de seu entorno: promover a excelência acadêmica e prestar serviços de qualidade; fazer pesquisa séria e produzir conhecimento útil para o desenvolvimento social; ser uma instituição da democracia e da cidadania.

A missão da universidade pública brasileira aponta para alguns aspectos, que por sua vez, influenciam na tomada de decisão quanto à elaboração da política universitária de ensino, pesquisa, extensão e, também, de gestão. Em linhas gerais, o texto da missão nos documentos analisados traz em seu bojo as seguintes ações, as quais a universidade se compromete a cumprir, como promover: produção e socialização do conhecimento, formação profissional, consciência crítica e cidadania, desenvolvimento regional, desenvolvimento sustentável, inovação e excelência acadêmica, melhoria na qualidade de vida, sociedade igualitária e democracia, ética, desenvolvimento humano e sociocultural, responsabilidade social, desenvolvimento econômico, solidariedade nacional e internacional. A tabela 3 apresenta uma visão geral do que pretende a universidade pública brasileira em termos seu compromisso social e educacional, a partir de sua missão.

Tabela 3. Visão geral da missão nas IES Federais e Estaduais (frequência) nos PDI's.

\begin{tabular}{lcc}
\hline Categorias & $\begin{array}{c}\text { Federais } \\
(\boldsymbol{\%})\end{array}$ & $\begin{array}{c}\text { Estaduais } \\
(\boldsymbol{\%})\end{array}$ \\
\hline Produzir e socializar conhecimentos & 100 & 100 \\
\hline Formação profissional & 43 & 94 \\
\hline Consciência crítica, cidadania e democracia & 43 & 50 \\
\hline Desenvolvimento regional & 30 & 100 \\
\hline Desenvolvimento sustentável & 24 & 70 \\
\hline Inovação e excelência acadêmica & 24 & - \\
\hline Melhoria da qualidade de vida & 16 & 23 \\
\hline Desenvolvimento humano e sociocultural & 13 & 56 \\
\hline Responsabilidade social & 11 & - \\
\hline Desenvolvimento econômico & 8 & 56 \\
\hline Transformação social & - & 50 \\
\hline
\end{tabular}

Fonte: PDI das universidades federais e estaduais.

Não há como negar que a missão primeira da universidade pública brasileira esteja relacionada com a produção do conhecimento. As declarações de missão, pela forma que consta nos documentos, delineiam as ações da IES para a produção, sistematização e difusão do conhecimento científico, tecnológico, artístico e humanístico, por meio da indissociabilidade do ensino, da pesquisa e da extensão.

\begin{tabular}{l|l|l|l} 
Rev. Inter. Educ. Sup. & Campinas, SP & v.3 & n.2
\end{tabular}

p.357-278 maio/ago. 2017 
De modo geral, os textos analisados indicam que as universidades têm como visão a excelência institucional e acadêmica, ser reconhecida por sua dinamicidade e qualidade na prestação de serviços educacionais, pelo desejo de ultrapassar padrões consagrados como excelentes e pela expansão e aperfeiçoamento do capital intelectual da sociedade. Para tanto, as instituições propõem ampliar e aperfeiçoar a mobilidade interinstitucional, inovar o planejamento, a produção, a gestão e avaliação, redesenhar e implementar uma política de comunicação, intensificação de meios e visibilidade institucional.

Os principais valores relacionados pelas instituições, tal como posto nos Planos de Desenvolvimento Institucional, também como construtos da missão, são os seguintes: autonomia, qualidade, inovação, atuação, internalização, independência, eficiência, ambiente de boa convivência, responsabilidade, comprometimento, respeito à liberdade, incentivo à participação, inclusão, democracia, planejamento, transparência, ética.

Os dados da tabela 3 nos revelam o nível de importância das categorias para as universidades por meio dos documentos analisados. A categoria "produção e distribuição do conhecimento" aparece como a principal missão, numa frequência de 100\% dos documentos. Assim, valemonos da afirmação de que o conhecimento é o diferencial entre a espécie humana e as outras espécies. Reconhecemos, a partir disso, que as universidades têm desafios para cumprir essa sua primeira e mais importante missão. Os principais desafios dizem respeito às diferenças regionais, ao quadro de docentes efetivos e a titulação e a assimetria no financiamento, a infraestrutura, equipamentos, laboratórios, bibliotecas, centros de pesquisa. As limitações da universidade a impõe a tornar insuficientes os serviços de excelência que deveria prestar à sua comunidade e à comunidade de seu entorno. Nesse sentido, concordamos com Goergen (2006), quando reconhece que a primeira e mais fundamental responsabilidade social da universidade está relacionada às atividades de investigação e docência em qualquer área. Para o autor, a razão é muito simples, porque essas são as duas atividades básicas da universidade. Assim, o foco da responsabilidade social deve recair sobre o que ela sabe, pode e deve fazer. Vale ressaltar, que a produção do conhecimento precisa ser crítica, criativa e competente; e será consistente se fundada num processo de competência simultaneamente técnica, criativa e crítica (SEVERINO, 2002).

Outras categorias foram identificadas nos PDI, indicando outros compromissos da universidade, levando-nos a acreditar na relevância da universidade para o desenvolvimento da sociedade, conforme assinala Goergen (2006), embora a conexão entre conhecimento e desenvolvimento não seja fácil e seja, muitas vezes, mal entendida. Podemos situar as demais categorias nesta ordem: exercício profissional (43,2\% nas federais e 94,4\% nas estaduais); formação da consciência crítica e cidadania (43,2\% nas federais e $23 \%$ nas estaduais); desenvolvimento regional (30\% nas federais e 100\% nas estaduais); desenvolvimento sustentável (24,3\% nas federais e $70 \%$ nas estaduais); inovação e excelência acadêmica (aparece apenas nas federais, em 24,3\%); melhoria da qualidade de vida (16,2\% nas federais e 
$23 \%$ nas estaduais); consolidação da democracia (16,2\% nas federais e 50\% nas estaduais); desenvolvimento humano e cultural (13,3 \% nas federais e 56\% nas estaduais); responsabilidade social (11\% apenas nas federais); desenvolvimento econômico $(8,1 \%$ nas federais e $56 \%$ nas estaduais).

Cabe identificar as categorias que aparecem apenas nos documentos das universidades federais: inovação e excelência acadêmica; responsabilidade social. E, ainda, as categorias que aparecem apenas nos documentos das universidades estaduais: transformação social; patrimônio imaterial. Poderíamos arriscar em dizer que a missão das universidades aqui apresentadas remete, em certa medida, para um equilíbrio em termos de proposituras, no sentido de essas cumprirem seu compromisso social, objetivando ensino, pesquisa e extensão de qualidade a serviço do desenvolvimento social, cultural, econômico e ambiental.

$\mathrm{Na}$ atual conjuntura, o cenário específico em que se encontra a sociedade brasileira é aquele desenhado por um intenso processo de globalização econômica e cultural, conduzido pela expansão da economia capitalista, que se apoia política e ideologicamente no paradigma neoliberal. Por isso, a tendência mundial é impor aos países a priorização da lógica do mercado na condução da vida social. Em relação à missão da educação, em especial a educação superior, em decorrência do imperialismo da sociedade capitalista, parece prevalecer a teoria do capital humano, ou seja, a da preparação de profissionais para o mercado de trabalho. Por sua vez, a ideologia neoliberal encontra apoio teórico nas teses filosóficas que consideram que vivemos uma nova era, aquela da pós-modernidade, caracterizada pelas incertezas do campo social. A modernidade, ao contrário da sociedade atual de rápidas e intensas mudanças, foi um tempo de grande segurança e forte identidade das instituições de ensino superior e da educação superior em si mesma, isto é, havia um consenso essencial, para além da diversidade dos sistemas de ensino superior, acerca do que era educação superior e acerca dos seus objetivos educacionais, sociais e políticos. Época de integração política das instituições no âmbito do Estado e a consolidação deste como instância central de regulação (MAGALHÃES, 2006; SEVERINO, 2008).

À medida que se foi caminhando para além da modernidade foram se instalando dúvidas acerca daquilo que é considerado conhecimento e seus fins (MAGALHÃES, 2006), os quais têm gerado grande impacto e tensões no campo do ensino superior, e que foi assim, redefinindo os seus papéis sociais e educacionais e as suas missões institucionais. Neste sentido, não está superada a ideia do que seja o conhecimento produzido na universidade e quais seus fins e a quem este conhecimento possa estar a servir. Para Oliveira (2006), as universidades públicas lutam entre ajustar-se às políticas e missões da educação superior e às demandas do mercado e desenvolver um projeto político próprio, coerente com a construção da autonomia e a democracia. Para tanto, conforme Goergen (2003), o projeto de ensino e pesquisa da universidade precisa preservar o sentido social, onde a perspectiva da responsabilidade implica um repensar da universidade no horizonte de seu sentido igualitário. 
Porém, o risco que ela corre é o de tornar-se, por força desse processo induzido de ajuste e regulação do sistema, uma universidade muito dependente das imposições políticas e das metas do poder executivo do país, mercantilizando sua produção acadêmica. Oliveira (2006) reconhece que, nesse processo de ajustamento, de sobrevivência e de desenvolvimento institucional, há indícios de que muitas universidades estejam assumindo perfil mais funcional e pragmático, o que pode distanciá-las do ideal de universidade como instituição social, que tem como objetivo produzir conhecimentos para contribuir com o processo de emancipação da sociedade.

A discussão em torno da missão da educação superior coloca a universidade em significados ambivalentes: de um lado, a universidade vista como fábrica do conhecimento; de outro lado, a universidade pensada como instituição para o desenvolvimento humano e cultural. Para Velho (1999, p. 135), a lógica da tendência utilitarista da universidade tende a reduzir a construção do conhecimento à produção de conhecimento mercadológico, ou seja, a universidade diretamente ligada ao setor produtivo, na consolidação da "fábrica do conhecimento".

Entendemos, portanto, que a missão da universidade é, em primeiro lugar, tornar-se um lugar de ideias e construção do conhecimento, construção mesmo no sentido real da palavra, e não um espaço de ideias sem propostas reais e exequíveis na solução dos problemas sociais. Em segundo lugar, ser um espaço comprometido com o ensino, a pesquisa e extensão e, por conseguinte, um ambiente promotor dos avanços do conhecimento útil, para além da utopia, aplicável às realidades sociais, para ajudar a resolver os problemas mais urgentes e para contribuir na melhoria da qualidade de vida. É objetivo da universidade, neste processo, tornar-se uma instituição com estratégias eficientes e efetivas de gestão e de busca de novos recursos para o cumprimento de sua missão.

\section{CONSIDERAÇÕES FINAIS}

As declarações de princípios, objetivos e finalidades e, também, de missão postuladas tanto nos Estatutos quanto nos Planos de Desenvolvimento Institucional analisadas neste estudo, levam à reflexão do real papel da universidade neste tempo de contradições e incertezas. Os documentos são uma forte referência para as instituições, pois neles estão ditas e oficializadas as principais preocupações da gestão no cumprimento da missão da educação superior.

A partir do estudo dos documentos, podemos perceber que a universidade pública brasileira identifica-se como uma instituição que busca a excelência acadêmica em todas as suas áreas de atuação: ensino, pesquisa e extensão. Neste sentido, estão declarados os principais atributos da missão: a produção do conhecimento por intermédio da pesquisa, a formação

v.3

n.2

p.357-278
maio/ago. 2017 
profissional por meio do ensino e a responsabilidade social a partir da extensão. Lembramos que sua missão dificilmente se consolida se estes processos estiverem dissociados.

O papel das universidades no plano de desenvolvimento da nação é declarado na missão de acordo com a dinâmica cultural, social, política, institucional e econômica. O conhecimento gerado neste contexto tem seu valor social quando é revertido em inovação para o cumprimento de sua responsabilidade social, no sentido de promoção social, ambiental e cultural.

A geração do conhecimento está declarada em todos os textos analisados, sendo, dessa forma, considerada a principal função das IES na prática do ensino, da pesquisa e da extensão. Se há a crítica em torno da pouca utilidade dos resultados das investigações, há também a crítica em relação à finalidade do conhecimento advindo desse processo. Severino (2008), por exemplo, admite a existência de um conflito dilemático: o confronto entre a educação pautada nas premissas da teoria do capital humano e uma educação que se identifica com a teoria da emancipação humana. De um lado, uma educação que se coloca a serviço do mercado, como um mero mecanismo de produção para fins empresariais e, de outro lado, uma educação que se coloca a serviço da construção de uma condição de existência mais humanizada, onde o trabalho é uma mediação essencial do existir histórico das pessoas.

Vale ressaltar, portanto, a partir dos estudos teóricos e análise de documentos institucionais, que a natureza a gestão universitária é construída segundo condicionantes políticoinstitucionais, econômicos e culturais; e que estão articulados de forma a delinear a estrutura e funcionamento da gestão, como também, de toda a política universitária.

\section{REFERÊNCIAS}

BARBIERI, Carlos. BI: Business intelligence: modelagem e tecnologia. Rio de Janeiro: Axcel Books do Brasil, 2001.

BARDIN, Laurence. Análise de Conteúdo. Lisboa, Portugal: Edições 70, LDA, 2009.

BORDIGNON, Luciane Spanhol; AFONSO, Mariangela Rosa; FRANCO, Maria Estela Dal Pai. Gestão universitária: qualidade, investigação científica e inovação educacional. Revista Gestão Universitária na América Latina: Revista GUAL, v 5, p. 83-103, 2012.

BRASIL. Constituição Federal de 1988. Brasília, DF: Senado Federal, 1988.

BUARQUE, Cristovam. A universidade na encruzilhada. In: Seminário: por que e como reformar? Brasília: UNESCO/Brasil/Ministério da Educação, 2003.

v.3

n.2

p.357-278


CATANI, Afrânio Mendes; OLIVERIA, João Ferreira de. A universidade pública no Brasil: identidade e projeto institucional em questão. Avaliação, v. 4, n. 4, p. 31-36, 1999.

CHAUÍ, Marilena de Souza. A universidade pública sob nova perspectiva. Conferência de abertura da 26a reunião anual da ANPED, Poços de Caldas, 5 de outubro de 2003.

CHIARINI, Túlio; VIEIRA, Karina Pereira. Universidades como produtoras de conhecimento para o desenvolvimento econômico: sistema superior de ensino e políticas de CT\&I. RBE, Rio de Janeiro, v. 66, n. 1, p. 117-132, jan./mar. 2012.

CORREIA, Fernanda; AMARAL, Alberto; MAGALHÃES, António. Diversificação e diversidade dos sistemas de ensino superior: o caso português. Matozinhos-Portugal: Cipes, 2000.

DENZIN, Normam K.; LINCOLN, Yvonna S. O planejamento da pesquisa qualitativa: teorias e abordagens. Porto Alegre: Artmed, 2006.

DIAS SOBRINHO, José. Dilemas da educação superior no mundo globalizado: sociedade do conhecimento ou economia do conhecimento? São Paulo: Casa do Psicólogo, 2005.

DIAS SOBRINHO, José. Universidade e novos modos de produção, circulação e aplicação do conhecimento. Avaliação, v. 19. n. 3, p. 643-662, nov. 2014.

DIAS SOBRINHO, José. Universidade fraturada: reflexões sobre conhecimento e responsabilidade social. Avaliação, v. 20, n. 3, p. 581-601, nov. 2015.

FERREIRA, Vitor F. Universidade e inovação tecnológica (Editorial). Quim. Nova, v. 25, n. 2, p. $179,2002$.

FINGER, Almeri Paulo. Gestão de universidade: novas abordagens. Curitiba: Champagnat, 1997.

GOERGEN, Pedro. Universidade e compromisso social. In: RISTOFF, Dilvo; SEVEGNAN, Plamira. Educação superior em debate: universidade e compromisso social. Brasília, DF: Instituto Nacional de Estudos e Pesquisas Educacionais Anísio Teixeira, 2006. p. 65-95.

GOERGEN, Pedro. Universidade e responsabilidade social. In: LOMBARDI, José Claudinei (Org.). Temas de pesquisa em Educação. Campinas: Autores Associados, 2003.

MAGALHÃES, António M. et al. A reconfiguração da gestão universitária em Portugal. Educação, Sociedade \& Culturas, n. 41, p. 7-23, 2014.

MAGALHÃES, António M. A Identidade do Ensino Superior: a Educação Superior e a Universidade. Revista Lusófona de Educação, n. 7, p. 13-40, 2006.

v.3

n. 2

p. $357-278$


MAÑAS, Antonio Vico. Estratégia e planejamento em instituições de ensino superior. In: NETO, João Pinheiro de Barros (Org.). Administração de instituições de ensino superior. Campinas: Alínea, 2014.

MEYER JÚNIOR, Victor. Planejamento Estratégico: uma renovação na gestão das instituições universitárias. Brasília, DF: ABMES, 1991.

MINAYO, Maria Cecília de Souza (Org.). Pesquisa Social: teoria, método e criatividade. Petrópolis: Vozes, 2001.

OLIVEIRA, João Ferreira de. Reforma da educação superior: mudanças na gestão e metamorfose das universidades públicas. In: PEREIRA, Filomena M. de A.; MULLER, M. Lúcia R. Educação na interface relação estado/sociedade. Cuiabá: EDUFMT/Capes, 2006. v. 1, p. 11-21.

PIRES, Hindenburgo Francisco. Universidade: a dialética do mercado e da sociedade. Revista Advir, n. 9, p. 05-07, 1996.

SANTOS, Boaventura de Sousa. A universidade no século XXI: para uma reforma democrática e emancipatória da universidade. São Paulo: Cortez, 2005.

SANTOS, Boaventura de Sousa. Pela mão de Alice: o social e o político na pósmodernidade. São Paulo: Cortez, 1995.

SCAGLIONE, Vera Lúcia Telles; NITZ, Marcelo. A avaliação da educação superior e a gestão universitária. In: COLOMBO, Sonia Simões (Org.). Gestão universitária: os caminhos para a excelência. Porto Alegre: Penso, 2013. p. 179.

SEVERINO, Antônio Joaquim. Educação e universidade: conhecimento e construção da cidadania. Interface: Comunicação, Saúde, Educação, v. 6, n. 10, p. 117-124, fev. 2002.

SEVERINO, Antônio Joaquim. O ensino superior brasileiro: novas configurações e velhos desafios. Educar, Curitiba, n. 31, p. 73-89, 2008.

SILVEIRA, Zilneide Simas; BIANCHETTI, Lucídio. Universidade moderna: dos interesses do Estado-nação às conveniências do mercado. Revista Brasileira de Educação, v. 21, n. 64, p. 79-99, jan./mar. 2016.

TRINDADE, Hélgio. Universidade em perspectiva: sociedade, conhecimento e poder. Revista Brasileira de Educação, n. 10, p. 5-15, jan./abr. 1999.

TURBAN, Efraim et al. Business intelligence: um enfoque gerencial para a inteligência do negócio. Porto Alegre: Bookman, 2009.

VAHL, Teodoro Rogério. O processo decisório e a gestão das universidades federais brasileiras. Educação Brasileira, Brasília, DF, v. 12, n. 2, p. 107-127, 1990. 
VELHO, Gilberto. Universidade e pluralismo sociocultural. In: OLINTO, H. K.;

SCHOLLHAMMER, K. E. Novas epistemologias: desafios para a universidade do futuro.

Rio de Janeiro: Ed. NAU; PUC-Rio, 1999.

\section{${ }^{\mathrm{i}}$ Sobre a autora}

Raimunda Maria da Cunha Ribeiro

E-mail: raicribeiro@ig.com.br / ORCID: http://orcid.org/0000-0001-6196-731X

Universidade Estadual do Piauí - Brasil

Doutorado em Educação pela Pontifícia Universidade Católica do Rio Grande do Sul [PUC-RS] 